\title{
Bio-electrolytic sensor for rapid monitoring of volatile fatty acids in anaerobic
} digestion process

\author{
Jin, Xiangdan; Li, Xiaohu; Zhao, Nannan; Zhang, Yifeng; Angelidaki, Irini
}

Published in:

Water Research

Link to article, DOI:

10.1016/j.watres.2016.12.045

Publication date:

2017

Document Version

Peer reviewed version

Link back to DTU Orbit

Citation $(A P A)$ :

Jin, X., Li, X., Żhao, N., Zhang, Y., \& Angelidaki, I. (2017). Bio-electrolytic sensor for rapid monitoring of volatile fatty acids in anaerobic digestion process. Water Research, 111, 74-80.

https://doi.org/10.1016/j.watres.2016.12.045

\section{General rights}

Copyright and moral rights for the publications made accessible in the public portal are retained by the authors and/or other copyright owners and it is a condition of accessing publications that users recognise and abide by the legal requirements associated with these rights.

- Users may download and print one copy of any publication from the public portal for the purpose of private study or research.

- You may not further distribute the material or use it for any profit-making activity or commercial gain

- You may freely distribute the URL identifying the publication in the public portal 
1 Bio-electrolytic sensor for rapid monitoring of volatile fatty acids in anaerobic digestion process

3

4 Xiangdan Jin, Xiaohu Li, Nannan Zhao, Yifeng Zhang*, Irini Angelidaki

5 Department of Environmental Engineering, Technical University of Denmark, DK-2800

6 Kongens Lyngby, Denmark

$7 \quad *$ Corresponding author:

8 Dr. Yifeng Zhang

9 Department of Environmental Engineering, Technical University of Denmark, Denmark

10 Tel: $(+45) 45251429$.

11 Fax: (+45) 45933850.

12 E-mail address: yifz@env.dtu.dk 
This study presents an innovative biosensor that was developed on the basis of a microbial electrolysis cell for fast and reliable measurement of volatile fatty acids (VFA) during anaerobic digestion (AD) process. The bio-electrolytic sensor was first tested with synthetic wastewater containing varying concentrations of VFA. A linear correlation $\left(\mathrm{R}^{2}=0.99\right)$ between current densities $(0.03 \pm 0.01$ to $\left.2.43 \pm 0.12 \mathrm{~A} / \mathrm{m}^{2}\right)$ and VFA concentrations $(5-100 \mathrm{mM})$ was found. The sensor performance was then investigated under different affecting parameters such as the external voltage, VFA composition ratio, and ionic strength. Linear relationship between the current density and VFA concentrations was always observed. Furthermore, the bio-electrolytic sensor proved ability to handle interruptions such as the presence of complex organic matter, anode exposure to oxygen and low $\mathrm{pH}$. Finally, the sensor was applied to monitor VFA concentrations in a lab-scale AD reactor for a month. The VFA measurements from the sensor correlated well with those from GC analysis which proved the accuracy of the system. Since hydrogen was produced in the cathode as byproduct during monitoring, the system could be energy self-sufficient. Considering the high accuracy, short response time, long-term stability and additional benefit of $\mathrm{H}_{2}$ production, this bio-electrolytic sensor could be a simple and cost-effective method for VFA monitoring during AD and other anaerobic processes.

Keyword: Volatile fatty acid; Biosensor; Microbial electrolysis cell; Anaerobic digestion; Hydrogen 


\section{Introduction}

Biogas, an alternative to fossil fuels, is becoming a promising source of renewable energy worldwide. In Europe, there are more than 14500 biogas plants by 2014 with total installed capacity of 7857 MWel (Dahlin et al., 2015). However, process instability caused by clogging, foaming and ammonia inhibition is often encountered in anaerobic digestion (AD), which may cause serious economic losses and prevent this technology from being widely applied. To prevent such problem and to ensure the biogas unit a long life-span, monitoring of the AD process is crucial. Parameters like volatile fatty acid (VFA) concentrations, $\mathrm{pH}$, biogas yield, biogas composition and alkalinity are commonly used as indicators of the complex biochemical process (Li et al., 2014). Among those indicators, it is widely acknowledged that the concentration of VFAs in the digester is prone to be a more meaningful indicator of the process status (Falk et al., 2015). Several off-line methods for VFA monitoring such as titration method (Purser et al., 2014), GC (Boe et al., 2007), high performance liquid chromatography (HPLC) and mid-infrared spectroscopy (Falk et al., 2015) have been developed. However, these methods are time consuming, inaccurate, expensive and typically tested manually. There are also a few online VFA monitoring systems based on the aforementioned methods (Boe and Angelidaki, 2012). Nevertheless, those systems often require complex equipment and careful maintenance, or need difficult sample preparation, which prevents their widely application. Therefore, development of an efficient, accurate and cost-effective VFA sensing system is crucial for the application of AD technology.

In recent years, bioelectrochemical systems (BESs) have demonstrated great potential to be alternatives for water quality measurement. In particular, microbial fuel cell, a typical BES, has been applied as biosensors for monitoring biochemical oxygen demand (BOD) (Zhang and Angelidaki, 
57 2011), dissolved oxygen (DO) (Zhang and Angelidaki, 2012), microbial activity (Zhang and 58 Angelidaki, 2011), toxic components (Shen et al., 2013; Jiang et al., 2015), and even VFA

concentrations (Kaur et al., 2013). BES-based biosensors have attracted great attention due to the advantages of cost-effective, rapid, sustainable and portable. The first demonstration of VFAs quantitative measurement in a MFC was presented by Kaur et al (2013). They further modified the anode by the immobilization of bacteria to ensure the sensor's stability and repeatability (Kaur et al., 2014). However, the detection range is quite limited for real application which is less than $80 \mathrm{mg} / \mathrm{L}$ and it would still function as a sensor of total organic matter instead of VFAs with real wastewater. To solve these problems, a VFA biosensor based on the principle of a microbial desalination cell (MDC) was proposed by our group which could detect a wide range of VFAs and eliminate the effect of sample matrix and complex organic matter (Jin et al., 2016). Nevertheless, the response time of the sensor could be shortened as well as the complex three-chambered architecture could be simplified further.

In this study, an innovative biosensor based on a microbial electrolysis cell (MEC) was developed to monitor VFA concentrations during AD process. The bio-electrolytic sensor was constituted of only two chambers and the synthetic wastewater was dosed into the cathode chamber. An external voltage was supplied to accelerate the transportation of VFAs from the cathode to anode through an anion exchange membrane (AEM). With such system, the response time and capital cost could be greatly reduced compared to those of the previous MDC-based VFA sensor. Furthermore, $\mathrm{H}_{2}$ could be produced at the cathode during the monitoring activity, which may partly compensate the energy used for powering the sensor. The aim of the present study is to provide proof-of-concept evidence that the bio-electrolytic sensor can be an alternative to the traditional complex and time-consuming analytical methods for the real-time detection of VFA concentrations in anaerobic process. With this purpose, the 
current response of bio-electrolytic sensor to various VFA concentrations in the artificial wastewater (mimicking $\mathrm{AD}$ effluent) was tested in terms of response time, detection range, sensitivity and operational stability. The effect of external voltage, VFA composition, and ionic strength on the performance of the sensor was investigated. The interference such as the presence of complex organic matter, anode exposure to oxygen and the effect of low $\mathrm{pH}$ on the system performance was explored. Finally, effluent from a lab-scale AD reactor fed with manure and industrial food-wastes was detected by the bio-electrolytic sensor for 30 days to verify the sensor's reliability. The application of the bioelectrolytic sensor might have the potential to supply an efficient way to control AD process and bring economic benefit.

\section{Material and methods}

\subsection{Biosensor Setup and Operation}

Two double-chamber reactors constructed of nonconductive polycarbonate plates were used in this study. The dimensions of the anode and cathode chambers were the same $(8 \times 8 \times 4 \mathrm{~cm})$ for both reactors. Anion exchange membrane (AEM) (AMI 7001, Membrane international, NJ, 9×9 cm) was used to separate the two chambers. Prior to use, membranes were soaked overnight in $50 \mathrm{M} \mathrm{NaCl}$ solution, and then stored in distilled water until placed in the cell. The reactors were tightened by rubber gaskets and screws to avoid leakage. The anode electrode was made of carbon brush $(5.0 \mathrm{~cm}$ in diameter, $5.0 \mathrm{~cm}$ in length, Mill-Rose, USA) and was attached with biofilm since it was obtained from an existing microbial electrochemical system (Jin et al., 2016). The cathode electrode was a titanium woven wire mesh $\left(4 \times 5 \mathrm{~cm}, 0.15 \mathrm{~mm}\right.$ aperture, William Gregor Limited, London) coated with $0.5 \mathrm{mg} / \mathrm{cm}^{2} \mathrm{Pt}$. Rubber tubes were inserted for medium refill and gas collection. A power supply (HQ PS3003, 
101 Helmholt Elektronik A/S, Denmark) was used to provide an additional voltage to the circuit. The positive lead of the power source was connected to the anode electrode, and the negative lead was connected to a $10 \Omega$ resistance connecting the cathode electrode in the circuit (Fig. 1).
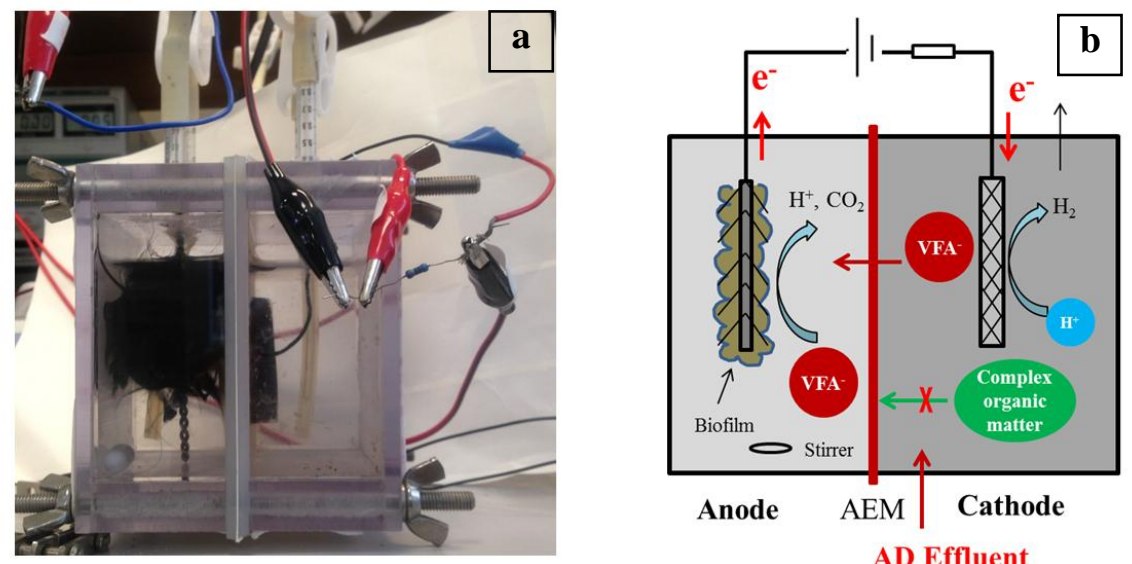

104

Fig. 1. Prototype (a) and schematic diagram (b) of the bio-electrolytic sensor.

The anode electrode was initially operated in the MFC mode without substrates for several days until the current density decreased below $0.1 \mathrm{~A} / \mathrm{m}^{2}$. During the experiment, the anode chamber was filled with approximately $220 \mathrm{~mL}$ of buffer solution $(\mathrm{pH}=7.22 \pm 0.17)$ containing $50 \mathrm{mM}$ phosphate buffer $\left(\mathrm{Na}_{2} \mathrm{HPO}_{4}, 4.33 \mathrm{~g} / \mathrm{L}\right.$; and $\left.\mathrm{NaH}_{2} \mathrm{PO}_{4}, 2.03 \mathrm{~g} / \mathrm{L}\right)$ and nutrient solution $\left(\mathrm{NH}_{4} \mathrm{Cl}, 0.31 \mathrm{~g} / \mathrm{L} ; \mathrm{KCl}, 0.13\right.$ $\mathrm{g} / \mathrm{L} ; 12.5 \mathrm{~mL}$ mineral solution and $12.5 \mathrm{~mL}$ vitamin solution) (Kvesitadze et al., 2012). The cathode was filled with $220 \mathrm{~mL}$ of synthetic wastewater as "artificial AD effluent", which was prepared with the same buffer solution containing varying concentrations of sodium acetate, sodium propionate and sodium butyrate (total VFAs ranges from 0 to $120 \mathrm{mM}$ ). To mimic real AD effluent, we set the concentration ratio of acetate, propionate and butyrate in "artificial AD effluent" at 5:1:1 which corresponds well to what is often measured in biogas plants (Hollinshead et al., 2014). In one set of tests, we tested the sensor with voltages at $0.3,0.5,0.8$ and $1.0 \mathrm{~V}$ to elucidate the effect of external voltage on the current generation. Then the effect of VFA composition on the system was studied: at 
118 three different concentration ratios (acetate: propionate: butyrate were 5: 1: $1\left(\mathrm{R}_{1}\right), 10: 10: 1\left(\mathrm{R}_{2}\right)$, and

119 20: 5: $\left.1\left(\mathrm{R}_{3}\right)\right)$. Subsequently the performance of the system was evaluated under different ionic strength

120 by adding $0,20,40$, and $80 \mathrm{mM} \mathrm{NaCl}$ to the artificial $\mathrm{AD}$ effluent. Both chambers were purged with $\mathrm{N}_{2}$

121 for 15 min to maintain anaerobic conditions prior to each batch run. Mixing was ensured in the anode

122 by a magnetic stirrer. A gas bag was connected with the cathode to collect the produced hydrogen. All

123 chemicals were of reagent grade. All experiments were carried out in duplicate at least at room 124 temperature $\left(22 \pm 2^{\circ} \mathrm{C}\right)$.

\section{2.2. Electrochemical Analyses and Calculations}

126 Conductivity and pH were measured by a CDM 83 conductivity meter (Radiometer) and a PHM

$127210 \mathrm{pH}$ meter (Radiometer), respectively. VFAs were measured using a GC with FID detection 128 (Agilent 6890). Hydrogen was analyzed by a GC-TCD fitted with a $4.5 \mathrm{~m} \times 3 \mathrm{~mm}$ s-m stainless column 129 packed with Molsieve SA (10/80). Voltage readings were taken every 10 mins using a digital 130 multimeter (Model 2700, Keithley Instruments, Inc.; Cleveland, OH, USA). Current density was 131 calculated as $i=I / A$, where $I$ (A) is the current calculated according to ohm's law and $A\left(\mathrm{~m}^{2}\right)$ is the 132 project surface area of the cathode. The amount of energy supplied to the sensor by the power source $133\left(W_{E}\right)$ and the energy efficiency $\left(\eta_{E}\right)$ relative to the electricity input were calculated as below:

$134 \quad W_{E}=\sum_{1}^{n}(I E \Delta t)$

$135 \eta_{E}=\frac{n_{\mathrm{H}_{2}} \Delta H_{H_{2}}}{W_{E}}$ 
Where $E(\mathrm{~V})$ is the voltage applied to the sensor, $\Delta t(\mathrm{~s})$ is the time increment for $\mathrm{n}$ data points

137 138

139

140

141

142

143

144

145

146

147

148

149

150

measured during the experiment, $n_{H 2}$ is the number of moles of hydrogen collected during operation, $\Delta H_{H 2}(285.83 \mathrm{~kJ} / \mathrm{mol})$ is the energy content of hydrogen based on the heat combustion.

\section{Results and Discussion}

\subsection{The Response of the Bio-electrolytic Sensor to Variations of VFA Concentrations}
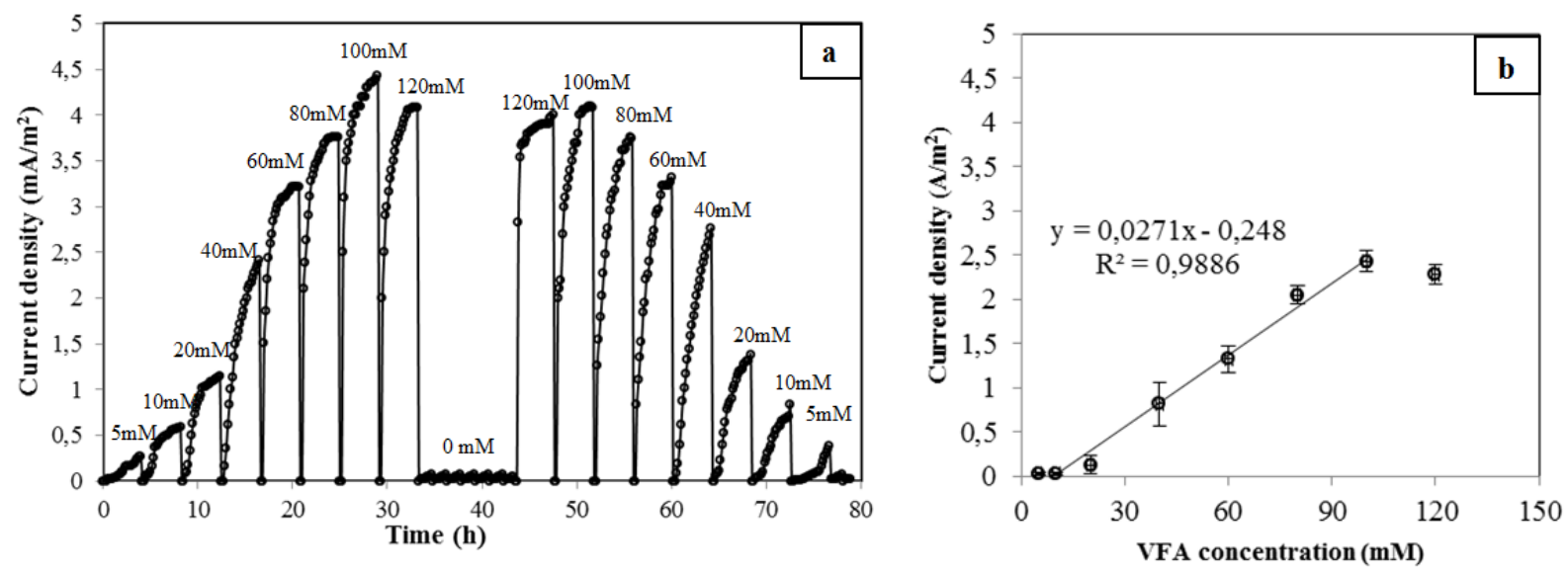

Fig. 2. Typical current density generation along with time from the biosensor (a) and the relationship between current density generated at $1 \mathrm{~h}$ and initial VFA levels in the artificial AD effluent (b).

The feasibility of the bio-electrolytic sensor was demonstrated with the artificial AD effluent at VFA concentrations ranging from 5 to $120 \mathrm{mM}$. Fig. 2a shows the current output along with time under varied VFA levels. The external voltage was $0.5 \mathrm{~V}$ and the concentration ratio of acetate, propionate and butyrate was 5:1:1. At each VFA concentration, it was found that the current density increased along with the time and reached to a platform within 4 hours. No significant increase was observed thereafter (data was not shown). It could be due to the establishment of equilibrium between VFA transportation from the cathode to anode chamber and VFA microbial consumption by anodic bacteria. 
151 Therefore, the reaction time of the sensor was chosen as $4 \mathrm{~h}$ for each sample in the following tests.

152 When organic matter was omitted from the artificial AD effluent in the cathode, the current density was 153 as low as observed during the starvation period $\left(<0.1 \mathrm{~A} / \mathrm{m}^{2}, 0 \mathrm{mM} \mathrm{VFA}\right)$. It was observed that the 154 maximum current density increased with VFA concentrations and vice versa within a certain VFA 155 concentration range $(5 \sim 100 \mathrm{mM})$. As indicated in Fig. 2a, the sensor showed a good reproducibility 156 independently the sequence of measurements and was not affected by VFA concentrations changed 157 from low to high or oppositely. Furthermore, the sensor recovered immediately after a period of 158 starvation and functioned well as soon as VFA were introduced into the sensor.

159 As shown in Fig. 2b, current densities obtained at $1 \mathrm{~h}$ were plotted as the function of initial VFA 160 concentrations. The current density increased from $0.03 \pm 0.01$ to $2.43 \pm 0.12 \mathrm{~A} / \mathrm{m}^{2}$ with VFA 161 concentrations increasing from 5 to $100 \mathrm{mM}$. A linear relationship was obtained with a high correlation 162 coefficient factor $\left(\mathrm{R}^{2}>0.98\right)$. No additional increase in the current output was observed when VFA 163 concentrations were above $100 \mathrm{mM}$, which suggests that the current density was saturated at higher 164 VFA concentrations. The current density obtained at 2, 3 or $4 \mathrm{~h}$ also showed linear relationship with VFA concentration (Fig. S1-3, Supplementary data). Since a relatively short response time was wished, 166 current densities generated at $1 \mathrm{~h}$ were focused in the subsequent tests. The results above clear demonstrated the applicability of the sensor for VFA monitoring. The detection range of the bio168 electrolytic sensor was up to $100 \mathrm{mM}$ which is much higher than that of MFC-based sensor (Kaur et al., 169 2013) and almost at the same level as that of the MDC-based sensor reported previously (Jin et al., 2016). It should be noted that the response time (i.e., $1 \mathrm{~h}$ ) achieved in this study was much shorter compared to that $(5 \mathrm{~h})$ of the previous MDC-based sensor. The response of the current density to VFAs in the cathode suggested that VFAs first transported through the AEM and then were utilized by the 173 anodic exoelectrogenic biofilm. Migration and difussion could be the main mechanisms responsible for 
174 such tranportation, and thus, the relatively quicker response time could be due to the enhanced

175 migration with external voltage supply (discussed later).

\section{3.2. Sensor Performance under Different Operational Conditions}

177 A series of experiments were conducted to study the individual effect of external voltage, VFA 178 composition ratio, and solution ionic strength on the sensor performance.

179
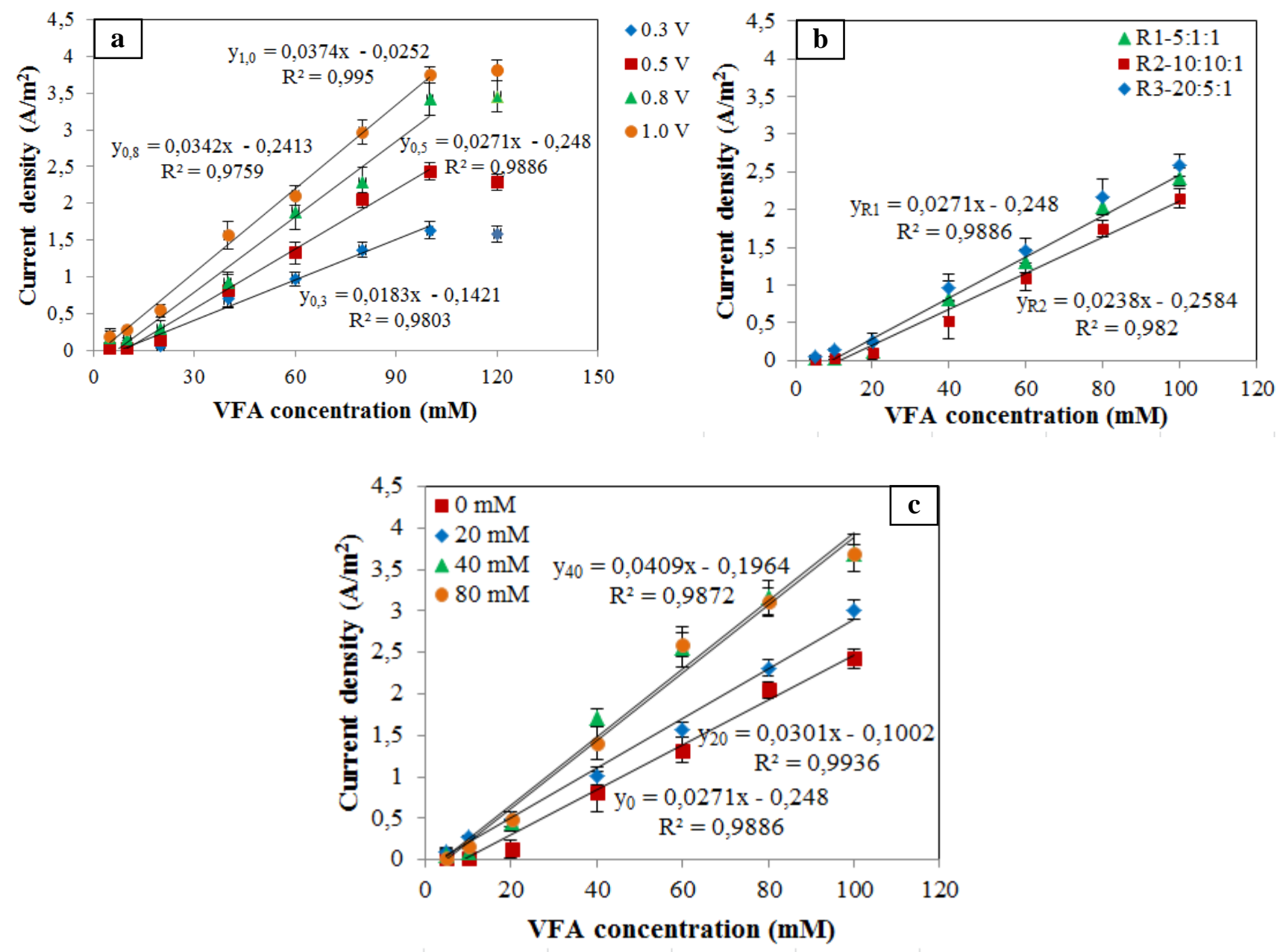

181 Fig. 3. Current densities against VFA levels under different external voltage (a), initial VFA concentration ratios 182 (b), and ionic strength with $\mathrm{NaCl}$ (c). 
Fig. 3a shows the current density generated at $1 \mathrm{~h}$ along with varied VFA concentrations under

different external voltage. The linear relationships between current densities $(0.02 \pm 0.01$ to $1.63 \pm 0.12$ $\mathrm{A} / \mathrm{m}^{2}$ at $0.3 \mathrm{~V} ; 0.03 \pm 0.01$ to $2.43 \pm 0.12 \mathrm{~A} / \mathrm{m}^{2}$ at $0.5 \mathrm{~V} ; 0.15 \pm 0.05$ to $3.42 \pm 0.21 \mathrm{~A} / \mathrm{m}^{2}$ at $0.8 \mathrm{~V} ; 0.19 \pm 0.07$ to $3.74 \pm 0.11 \mathrm{~A} / \mathrm{m}^{2}$ at $\left.1.0 \mathrm{~V}\right)$ and VFA concentrations $(5-100 \mathrm{mM})$ were observed at all the external voltages. Furthermore, the current density increased with the increasing external voltage. It was also found that the difference among the current densities observed with different external voltages was much larger at high VFA concentrations than that at low VFA concentrations. For instance, with 100 mM VFA in the artificial AD effluent, the current density generated at $1.0 \mathrm{~V}$ was $3.74 \pm 0.11 \mathrm{~A} / \mathrm{m}^{2}$, which was much higher than that obtained at $0.3 \mathrm{~V}\left(1.63 \pm 0.12 \mathrm{~A} / \mathrm{m}^{2}\right)$. However, while the initial VFAs were below $20 \mathrm{mM}$, the differences among the current densities under different voltages were not significant. It is due to that the substrate was the main limiting factor at low VFA concentrations while the external voltage turned to be dominant when sufficient substrate was supplied. The higher voltage applied the faster VFA transportation to the anode, which might explain the increase of current density with higher external voltage (discussed in later section). At the end of experiments, 14.0, 27.5, 34.0, and $41.5 \mathrm{~mL} \mathrm{H}_{2}$ was collected at $0.3,0.5,0.8$ and $1.0 \mathrm{~V}$, respectively. The energy efficiencies related to the electrical input were $137.6 \%, 158.6 \%, 103.3 \%$ and $120.8 \%$, respectively. The result was comparable to traditional MEC systems (Zhang and Angelidaki, 2014). Therefore, the bio-electrolytic sensor could realize energy self-sufficient with $\mathrm{H}_{2}$ production in addition to VFA monitoring. To achieve the highest energy efficiency, $0.5 \mathrm{~V}$ was selected as external voltage in the following tests.

Acknowledging that VFA composition might influence the anion transportation across the AEM and the anodic microbial communities as well as the sensor performance, the sensor was further tested at three different VFA ratios (i.e., $\mathrm{R}_{1}, \mathrm{R}_{2}$ and $\mathrm{R}_{3}$ ) to address such concerns. The correlation between current densities and VFA concentrations at different VFA composition is shown in Fig. 3b. Similar 
results were obtained at $\mathrm{R}_{1}$ and $\mathrm{R}_{3}$, and the regression function was still suitable. Comparatively, relatively lower current density was observed at $\mathrm{R}_{2}$ resulting in a slightly decrease of the slope of the linear function. It has been recently reported that the transportation rate of acetate was faster than those of propionate and butyrate through the AEM which can be anticipated due to the smaller molecule size of acetate (Zhang and Angelidaki, 2015). Moreover, propionate and butyrate degradations have been known to be thermodynamically less favorable as compared to acetate degradation (Yang et al., 2015). The proportion of acetate $(>70 \%)$ was much higher than the proportions of propionate and butyrate at $R_{1}$ and $R_{3}$ while the proportion of acetate $(<50 \%)$ was smaller at $R_{2}$, which might cause the decrease in current density at $\mathrm{R}_{2}$. Since the amount of acetate was always dominant in real AD effluent, the bioelectrolytic sensor is practicable in field application.

Subsequently our system was examined as a function of the ionic strength. Thus $\mathrm{NaCl}$ were added in the artificial $\mathrm{AD}$ effluent to study their impact on the sensor performance. Results are shown in Fig. 3c. The current density still displayed linear relationship with VFA levels at different ionic strengths. The current density generally increased with the increasing ionic strength, resulting in the change of the regression function. For example, by increasing the solution ionic strength from 20 to $40 \mathrm{mM}$ with $\mathrm{NaCl}$, the current density obtained at $100 \mathrm{mM}$ VFA increased from $3.01 \pm 0.11$ to $3.70 \pm 0.15 \mathrm{~A} / \mathrm{m}^{2}$. This could be due to the decrease of the internal resistance as result of the conductivity elevation (Fig. S4, Supplementary data) at high ionic strength. However, the current density ceased to increase when the $\mathrm{NaCl}$ concentration was higher than $40 \mathrm{mM}$, indicating the saturation of current density at this ionic strength level (Liu et al., 2005). Since the ionic strength in real AD effluent was usually higher than 80 mM (Cai et al., 2013; Sheets et al., 2014), the results from the system will be still valid. However, in practical applications the sensor may need calibration by taking practical environmental conditions into account such as wastewater was diluted. 
229
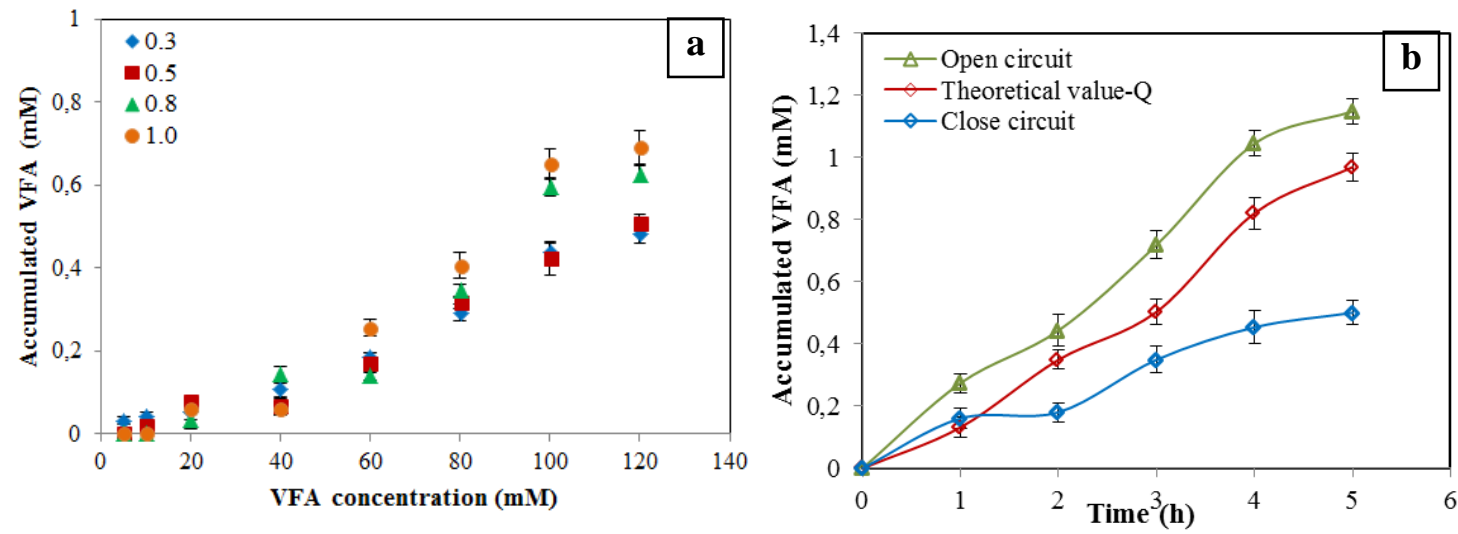

Fig. 4. Accumulated VFAs in the anode chamber at $1 \mathrm{~h}$ under different external voltage (a); Accumulated VFAs in the anode under different conditions: open circuit; close circuit and theoretical value calculated by the accumulated charge (b).

\subsection{Mechanism of VFA transportation}

The accumulated VFA concentration in the anode under different voltage was measured (Fig. 4a). It was indeed observed that higher voltage caused more VFA to accumulate in the anode under the same initial VFA concentration which is the dosed VFAs in the cathode at the beginning of each batch. Such observation was even clear when the initial VFA concentration was higher than $40 \mathrm{mM}$. Interestingly, at same applied voltage, the accumulated VFA concentration in the anode increased with the initial VFA concentration of the artificial AD effluent. The results imply that besides electricity driven migration, diffusion caused by concentration gradient might also be responsible for VFA transportation. Then the accumulated VFA in the anode was monitored under both open circuit and closed circuit $(E=0.5 \mathrm{~V})$ along with the operation time when the initial VFA in the artificial AD effluent was $60 \mathrm{mM}$ (Fig. 4b). VFA accumulation under open circuit confirmed the contribution of diffusion to the VFA transportation. Theoretically, most charge should be balanced by negative VFA ions migrating from the cathode to the anode chamber. Thus, the contribution of migration to the VFA transportation could be estimated on the basis of the accumulated charge (Q) during the monitoring. Notably, the actual 
247 concentration of the accumulated VFA in the anode was much lower than that under open circuit or

248 calculated according to the accumulated charge, which implied the substrate consumption by the anodic 249 exoelectrogenic biofilm. In addition, it was noticed that the accumulated VFA concentration in the 250 anode under close circuit did not increase further after $4 \mathrm{~h}$, indicating a dynamic equilibrium between 251 VFA consumption and transportation. This was consistent with the current density where a platform 252 was reached around $4 \mathrm{~h}$.

253 3.4. Sensor performance under different interference situation

254

255

256

257

258

259

260

261

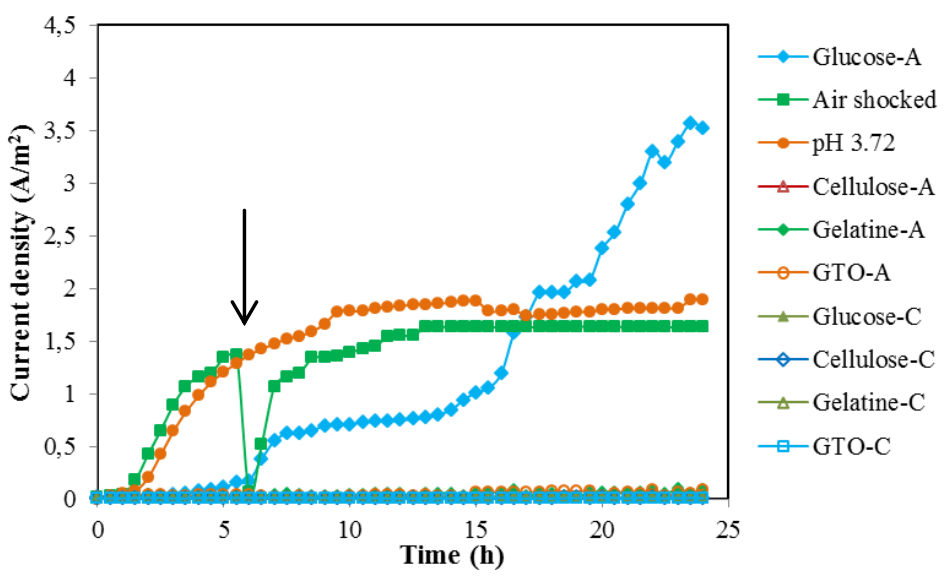

Fig. 5. Current density generation when organic matter was dosed in the cathode and anode, respectively; arrow indicates when air sparging was applied; $\mathrm{pH}$ of the cathode solution was adjusted to 3.72 .

It is of outmost importance for a sensor to be robust to interruptions. Fig. 5 shows the response of the sensor to different interferences. To test the selectivity of the sensor, we dosed a mixture of organic matter (e.g., glucose, cellulose, protein and lipid) instead of VFAs into the cathode or anode chamber, respectively. When $2 \mathrm{~g} / \mathrm{L}$ glucose was added in the anode, stepwise increases in current density were obtained. On the contrary, only background current density was observed when glucose was added into 
262 the cathode as sole organic matter. As glucose is nonionic it was retained by the AEM in the same 263 chamber where it was added. Likewise, $2 \mathrm{~g} / \mathrm{L}$ cellulose, $2 \mathrm{~g} / \mathrm{L}$ gelation or $10 \mathrm{~mL} / \mathrm{L}$ GTO in the cathode 264 didn't increase the current density. Comparatively, when some of them were dosed in the anode, very 265 low level of current density was observed since microorganisms may need a bit adaption time to 266 hydrolyze polymer into simple molecules. The results demonstrate the good selectivity of the bio267 electrolytic sensor, since the interference from complex organic matter could be avoided as the AD 268 effluent was fed into the cathode. It is one of the important advantages of the sensor developed in our 269 study compared to the previous MFC sensor in which the AD effluent is added into the anode chamber 270 (Kaur et al., 2013). Moreover, the sensor is able to detect a wide range of VFAs since only part of bulk 271 VFAs in the cathode transferred to the anodic biofilm. For assessing the recovery ability after a 272 possible disturbance, $12 \mathrm{~mL}$ air was injected to the anode using a syringe and the response of the sensor 273 was recorded. As shown in Fig. 5, anodic biofilm reacted immediately to air pulses by ceasing 274 electricity generation. After 1 hour the current density generation resumed which underlined the 275 resilience of the sensor. Subsequently, we investigated the sensor performance at low $\mathrm{pH}$ condition by 276 adjusting the $\mathrm{pH}$ of artificial $\mathrm{AD}$ effluent to 3.72. Results showed that the sensor performance was not 277 influenced by the low $\mathrm{pH}$ as proton transportation towards to anode was prevented by the AEM. 278 Therefore, the utilization of AEM and dosing artificial AD effluent in the cathode made the system 279 selective and robust.

\subsection{Verification of the sensor with effluents from real AD reactor}


283 the cathode of the bio-electrolytic sensor for measurement. The operational data for the CSTR and 284 characteristics of the effluent are listed in Table S1 (Supplementary data). VFA concentrations obtained 285 from our sensor and GC are summarized in Fig. 6. The fluctuation in VFA levels was observed through 286 the sensor with good sensitivity. The values obtained with the sensor agreed well with the total VFA 287 values measured by GC. ANOVA analysis detected no significant difference between the two groups $288\left(\mathrm{~F}=0.54>\mathrm{F}_{(30,29)}=0.11, \mathrm{P} \leq 0.05\right)$, which confirmed the good accuracy of the sensor. According to the 289 results, the sensor can easily handle samples from AD reactors with a wide range of VFA levels. 290 Especially, the sensor concept is simple which makes it potentially applicable to various anaerobic 291 processes. Furthermore, this bio-electrolytic sensor has been operated over 5 months in a stable manner without any maintenance service, which demonstrates the reliability of the sensor system.

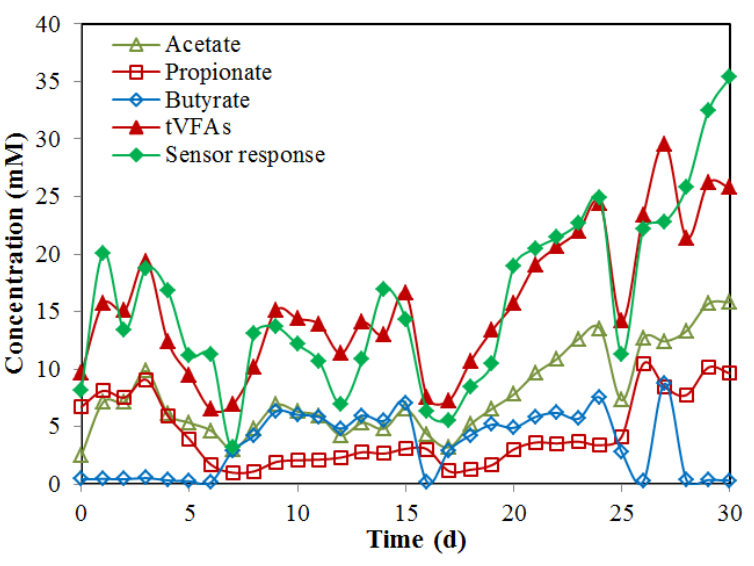

Fig. 6. Monitoring test of a lab-scale CSTR.

\section{Conclusion}

The present work demonstrated for the first time the feasibility of the MEC-typed sensor for VFA monitoring in $\mathrm{AD}$ process. Reproducible current densities as a function of different VFA concentrations over a wide range $(0-100 \mathrm{mM})$ were obtained. The external voltage, VFA composition and ionic strength affected the sensor performance. Nevertheless linear relationships between current 
300 density and VFA levels were always observed. The sensor had a high selectivity since complex organic

301 matter was retained by AEM which only allowed VFA transport through. Moreover it was robust to 302 interruptions such as low $\mathrm{pH}$ and resumed soon after expose to air. Hydrogen was produced during the 303 measurement which could compensate (or partly) the energy requirements of the sensor. Though the 304 bio-electrolytic sensor has a potential in monitoring biogas process, further improvements and 305 modifications such as more compact sensor and robust structure is necessary to fit the onsite and real 306 time monitoring.

\section{Acknowledgement}

The authors would like to acknowledge China Scholarship Council for the financial support. The 309 authors thank the technical assistance by Hector Gracia with analytical measurements and Viviana Negro for supplying AD effluents from her AD reactor. This research is supported financially by the

Danish Council for Independent Research (DFF-1335-00142).

\section{References}

313 Boe, K., Batstone, D.J., Angelidaki, I., 2007. An innovative online VFA monitoring system for the anerobic process, based on headspace gas chromatography. Biotechnol. Bioeng. 96(4), 712- 721.

Boe, K., Angelidaki, I., 2012. Pilot-scale application of an online VFA sensor for monitoring and control of a manure digester. Water Sci. Technol. 66(11), 2496-2503.

Cai, T., Park, S.Y., Racharaks, R., Li, Y., 2013. Cultivation of Nannochloropsis salina using anaerobic digestion effluent as a nutrient source for biofuel production. Appl. Energy. 108, 486-492. 
Dahlin, J., Herbes, C., Nelles, M., 2015. Biogas digestate marketing: Qualitative insights into the supply side. Conservation Recycl. 104, 152-161.

Falk, H.M., Reichling, P., Andersen, C., Benz, R., 2015. Online monitoring of concentration and dynamics of volatile fatty acids in anaerobic digestion processes with mid-infrared spectroscopy. Bioprocess Biosyst. Eng. 38(2), 237-249.

Hollinshead, W.D., Varman, A.M., You, L., Hembree, Z., Tang, Y.J., 2014. Boosting d-lactate production in engineered cyanobacteria using sterilized anaerobic digestion effluents. Bioresour. Technol. 169, 462-467.

Jiang, Y., Liang, P., Zhang, C., Bian, Y., Yang, X., Huang, X., Girguis, P.R., 2015. Enhancing the response of microbial fuel cell based toxicity sensors to $\mathrm{Cu}(\mathrm{II})$ with the applying of flowthrough electrodes and controlled anode potentials. Bioresour. Technol. 190, 367-372.

Jin, X., Angelidaki, I., Zhang, Y., 2016. Microbial electrochemical monitoring of volatile fatty acids during anaerobic digestion. Environ. Sci. Technol. 50 (8), 4422-4429.

Kaur, A., Kim, J.R., Michie, I., Dinsdale, R.M., Guwy, A.J., Premier, G.C., 2013. Microbial fuel cell type biosensor for specific volatile fatty acids using acclimated bacterial communities. Biosens. Bioelectron. 47, 50-55.

Kaur, A., Ibrahim, S., Pickett, C.J., Michie, I.S., Dinsdale, R.M., Guwy, A.J., Premier, G.C., 2014. Anode modification to improve the performance of a microbial fuel cell volatile fatty acid biosensor. Sens. Actuators, B 201, 266-273.

Kvesitadze, G., Sadunishvili, T., Dudauri, T., Zahariashvili, N., Partskhaladze, G., Ugrekhelidze, V., Tsiklauri, G., Metreveli, B., Jobava, M., 2012. Two-stage anaerobic process for bio-hydrogen and bio-methane combined production from biodegradable solid wastes. Energy. 37(1), 94-102. 
Li, L., He, Q., Wei, Y., He, Q., Peng, X., 2014. Early warning indicators for monitoring the process failure of anaerobic digestion system of food waste. Bioresour. Technol. 171, 491-494.

Liu, H., Cheng, S., Logan, B.E., 2005. Power Generation in Fed-Batch Microbial fuel cells as a function of ionic strength, temperature, and reactor configuration. Environ. Sci. Technol. 39(14), 5488-5493.

Purser, B.J., Thai, S.-M., Fritz, T., Esteves, S., Dinsdale, R., Guwy, A., 2014. An improved titration model reducing over estimation of total volatile fatty acids in anaerobic digestion of energy crop, animal slurry and food waste. Water Res. 61, 162-170.

Sheets, J.P., Ge, X., Park, S.Y., Li, Y., 2014. Effect of outdoor conditions on Nannochloropsis salina cultivation in artificial seawater using nutrients from anaerobic digestion effluent. Bioresour. Technol. 152, 154-161.

Shen, Y., Wang, M., Chang, I.S., Ng, H.Y., 2013. Effect of shear rate on the response of microbial fuel cell toxicity sensor to $\mathrm{Cu}(\mathrm{II})$. Bioresour. Technol. 136, 707-710.

Yang, N., Hafez, H., Nakhla, G., 2015. Impact of volatile fatty acids on microbial electrolysis cell performance. Bioresour. Technol. 193, 449-455.

Zhang, Y., Angelidaki, I., 2011. Submersible microbial fuel cell sensor for monitoring microbial activity and BOD in groundwater: focusing on impact of anodic biofilm on sensor applicability. Biotechnol. Bioeng. 108(10), 2339-2347.

Zhang, Y., Angelidaki, I., 2012. A simple and rapid method for monitoring dissolved oxygen in water with a submersible microbial fuel cell (SBMFC). Biosens. Bioelectron. 38(1), 189-194.

Zhang, Y., Angelidaki, I., 2014. Microbial electrolysis cells turning to be versatile technology: Recent advances and future challenges. Water Res. 56(1), 11-25. 
363 Zhang, Y., Angelidaki, I., 2015. Bioelectrochemical recovery of waste-derived volatile fatty acids and production of hydrogen and alkali. Water Res. 81, 188-195. 
Electronic Supplementary Material (for online publication only)
Click here to download Electronic Supplementary Material (for online publication only): Supplementary data.docx 